\title{
O Desenvolvimento dos Municípios Nordestinos Dedicados à Cotonicultura em Diferentes Paradigmas Produtivos no Período 2000-2010
}

http://dx.doi.org/10.21527/2237-6453.2019.47.301-323

Recebido em: 9/9/2017

Aceito em: 19/12/2018

\section{Paulo Thiago Nunes Bezerra de Meloํㅜ ${ }^{1}$ Hans Michael van Bellen²}

\begin{abstract}
RESUMO
O objetivo deste artigo é comparar os municípios nordestinos dedicados à cotonicultura convencional e à orgânica a partir das mudanças nos seus indicadores de desenvolvimento no período dos anos 2000 a 2010. A partir da discussão sobre a cotonicultura no Nordeste brasileiro, a contribuição teórica apresentada neste artigo repousa na compreensão de que os diferentes paradigmas no meio rural, convencional e orgânico, promovem incidências distintas no processo de desenvolvimento. A cotonicultura convencional e a orgânica podem promover distintos conjuntos de bens econômicos, socioculturais e ecológicos que dão base para um processo de desenvolvimento sustentável no meio rural. O presente estudo é de natureza descritiva e adota uma abordagem quantitativa na coleta e análise dos dados. Foram coletados dados secundários sobre o PIB, o IDH e a quantidade de domicílios com bens duráveis nos municípios analisados. Este estudo adota uma abordagem comparativa na análise dos resultados. O desenvolvimento dos municípios dedicados à cotonicultura convencional tem demonstrado uma orientação mais forte para o modelo de desenvolvimento sustentável do que os municípios dedicados à cotonicultura orgânica.
\end{abstract}

Palavras-chave: Desenvolvimento. Municípios. Cotonicultura. Sustentabilidade.

\section{THE DEVELOPMENT OF NORTHEASTERN MUNICIPALITIES DEDICATED TO COTONICULTURE IN DIFFERENT PRODUCTIVE PARADIGMS IN THE PERIOD 2000-2010}

\begin{abstract}
The aim of this article is to compare the Northeastern municipalities dedicated to conventional and organic cotton farming from the changes in their development indicators in the period from 2000 to 2010 . From the discussion on cotoniculture in Northeast of Brazil, the theoretical contribution presented in this article lays on the understanding that the different paradig$\mathrm{ms}$ in rural areas, conventional and organic, promote distinct results in the development process. Conventional and organic cotoniculture can promote distinct sets of economic, sociocultural and ecological outputs that provide the basis for a sustainable development process in rural areas. The present study is a descriptive one in nature and adopts a quantitative approach in data collection and analysis. Secondary data were collected on GDP, HDI and the number of households with durable goods in the analyzed municipalities. This study adopts a comparative approach in the results analysis. The development of municipalities dedicated to conventional cotoniculture has shown a stronger orientation for the sustainable development model than the municipalities dedicated to organic cotton production.
\end{abstract}

Keywords: Development. Municipalities. Cotoniculture. Sustainability.

\footnotetext{
${ }^{1}$ Doutor em Administração pela Universidade Federal de Santa Catarina (UFSC). Professor da Universidade Federal Rural de Pernambuco (UFRPE).pthiagoadm@hotmail.com

2 Doutor em Engenharia de Produção pela Universidade Federal de Santa Catarina (UFSC). Professor da Universidade Federal de Santa Catarina (UFSC). hansmichael.vanbellen@gmail.com
} 
O objetivo deste artigo é comparar os municípios nordestinos dedicados à cotonicultura convencional e à orgânica a partir das mudanças nos seus indicadores de desenvolvimento no período dos anos 2000 a 2010. No Nordeste, a área de transição entre os biomas caatinga e cerrado divide mais do que diferentes ecossistemas. Atualmente, essa área divide paradigmas distintos de desenvolvimento rural, localizando experiências de agricultura orgânica familiar na caatinga e experiências de agricultura convencional empresarial no cerrado, que compartilham a dedicação à cotonicultura como elemento comum.

A caatinga abriga organizações da sociedade civil que, com auxílios de ações governamentais, buscam fortalecer a agricultura familiar com base em princípios agroecológicos que resultam em produtos orgânicos (JALFIM et al., 2013). Por sua vez, o cerrado nordestino tornou-se parte da nova área de fronteira agrícola do país, que tem sido denominada de Mapitoba, acrônimo dos Estados do Maranhão, Piauí, Tocantins e Bahia.

As áreas da atual fronteira agrícola são caracterizadas principalmente pelo cultivo para exportação (AGUIAR; LIMA-FILHO; TORRES-JUNIOR, 2013). Nessa região, a produtividade de algodão era $58 \%$ menor que a média nacional durante a década de 80 do século 20, enquanto na década de 10 do século 21 sua produtividade têm sido $3 \%$ menor que a média nacional (CONAB, 2016). Nos sistemas agrícolas empresariais, a cultura de algodão acontece de maneira associada às culturas de milho e soja, orientadas para o comércio internacional.

Assim como as culturas de cana-de-açúcar e café foram utilizadas como fonte estratégica de recursos para o desenvolvimento de algumas regiões do país no passado, a cotonicultura também já foi, e voltou a ser recentemente, também uma fonte estratégica de recursos. O Brasil já foi um dos maiores exportadores de algodão e voltou a assumir essa posição mais recentemente, em virtude dos avanços tecnológicos que foram incorporados e ao reposicionamento das culturas nas áreas do cerrado central e nas áreas de fronteira agrícola no Nordeste.

A produção orgânica tem sido adotada como sistema produtivo para uma variedade de produtos agrícolas no Brasil, dentre os quais o algodão tem despertado interesse de organizações e produtores na caatinga nordestina. Tais organizações e produtores vêm desenvolvendo ações que buscam inserir a cotonicultura orgânica em cadeias produtivas que refletem os requisitos de desenvolvimento sustentável. Segundo Beltrão et al. (2010), as expectativas são de que o mercado de algodão orgânico cresça intensamente nos próximos anos. Nos últimos anos as empresas têm investido em tecnologias para usar algodão orgânico, levando ao crescimento da produção e do uso desse tipo de algodão, que ainda representa uma pequena parcela da produção global de algodão (BOSSLE et al., 2012).

A agricultura orgânica tem sido legitimada tanto pelos benefícios sociais para a saúde dos indivíduos, quanto pelos seus benefícios para o meio ambiente. Altieri e Nicholls (2012) ressaltam que a agricultura, em sua forma moderna e industrial, contribui para problemas ambientais, uma vez que é a responsável por $25 \%-30 \%$ das emissões de gases de efeito estufa, intensificando o problema da mudança climática. Além disso, a agricultura industrial torna a mão de obra um recurso dispensável, também sendo res- 
ponsável por problemas econômicos e sociais no meio rural, como a intensificação de desigualdades sociais e a desocupação de trabalhadores rurais, que buscam uma alternativa de vida nas periferias urbanas com condições precárias (SACHS, 2001).

No Brasil, o desenvolvimento rural tem sido buscado por meio de paradigmas distintos que contribuem para diferentes incidências nas dinâmicas de desenvolvimento regional. Há projetos de desenvolvimento rural que priorizam sistemas agrícolas industriais com uso intensivo de agrotóxicos, enquanto outros priorizam sistemas de produção orgânica baseados nos princípios da agroecologia, tendo como elemento-chave a promoção da biodiversidade (ALTIERI; NICHOLLS, 2012).

É relevante ressaltar a presença simultânea da cotonicultura convencional e da orgânica no Nordeste Brasileiro em razão da intensa distinção nas suas visões de mundo. Porto e Soares (2012) destacam que o cultivo de algodão é responsável pelos maiores gastos com agrotóxicos por estabelecimento agrícola no país, representando o uso intenso da química agrícola na produção convencional. Por sua vez, a cotonicultura orgânica tem sido reforçada no Nordeste, seja pela produção orgânica em monocultura ou sua inserção em sistemas diversificados sob gestão familiar. A partir da discussão sobre a cotonicultura no Nordeste brasileiro, a contribuição teórica apresentada neste artigo repousa na compreensão de que esses diferentes paradigmas no meio rural, convencional e orgânico, promovem diversas incidências no processo de desenvolvimento.

Para realizar a discussão proposta, o artigo está estruturado em quatro seções além desta introdução. A próxima apresenta o referencial teórico do estudo, discutindo a trajetória recente da cotonicultura, os seus aspectos econômicos e os socioambientais. A seção seguinte expõe o percurso metodológico adotado. Em seguida são apresentados os resultados e análises sobre os dados coletados. Por fim, o texto apresenta as conclusões e as referências bibliográficas empregadas no desenvolvimento da pesquisa.

\section{ASPECTOS MULTIDIMENSIONAIS DO DESENVOLVIMENTO}

A partir do fim da Segunda Guerra Mundial, as Nações Unidas adotaram o Produto Interno Bruto (PIB) para acompanhar o progresso econômico dos países, assumindo que as ideias de crescimento econômico e desenvolvimento eram sinônimas naquele período histórico (SIEDENBERG, 2003). O aumento do PIB ocorre, entretanto, em situações de sobre-exploração de recursos humanos e uso devastador dos recursos naturais, destacando o desalinhamento da relação entre o crescimento econômico e o desenvolvimento (HADDAD, 1999). Costumeiramente, a renda média da uma população (PIB per capita) e o PIB de uma localidade, representados pela soma dos valores dos bens e serviços produzidos em uma região e período, compreendem a dimensão econômica do desenvolvimento.

Em contextos com instituições jurídicas frágeis em relação aos direitos ambientais e sociais, é mais provável de observar o aumento do PIB pela exploração de trabalhadores e a utilização indiscriminada de recursos naturais nos sistemas produtivos (VEI$G A$, 2007). Nesse sentido, o aumento do PIB não reflete o dinamismo abrangente do desenvolvimento, pois tem maiores impactos quando estimula os sistemas produtivos das guerras em vez dos de pacificação, os sistemas corretivos de saúde pública em vez dos preventivos, os sistemas depreciativos do capital natural em vez dos generativos, os 
sistemas remunerativos de relações de trabalho em vez dos voluntários, entre outros motivos. Em suma, criar mazelas e suas correções tem sido mais estimulador, do ponto de vista do PIB, do que evitar tais dificuldades para as gerações futuras.

As atividades produtivas causadoras dos maiores prejuízos ao meio ambiente em termos de poluição e depreciação do capital natural são, segundo Hueting e Reijnders (2004), aquelas com maior contribuição no crescimento econômico. Os esforços para o crescimento econômico por meio do PIB parecem não ter aderência aos objetivos ambientais, sendo incoerentes à ideia de sustentabilidade e discutíveis para compreender o processo de desenvolvimento (LEUKHARDT; ALLEN, 2013). A principal preocupação na dimensão econômica é a alocação eficiente dos recursos em uma escala apropriada (VAN BELLEN, 2010).

Em um ponto de vista heterodoxo do processo de desenvolvimento, a dimensão social é discutida ressaltando a perspectiva da qualidade de vida. Nesse sentido, a principal questão do desenvolvimento é a manutenção do bem-estar em longo prazo, permitindo às gerações atuais e futuras desfrutar de uma boa qualidade de vida (BIJL, 2011). Conforme Amartya Sen (2000), um importante fator do desenvolvimento é a liberdade individual substantiva, ou seja, a capacidade humana dos indivíduos nas diversas situações da vida social. A dimensão social do desenvolvimento destaca a extensão de direitos ao conjunto dos cidadãos, resultando em uma cidadania efetiva (SACHS, 2001). As preocupações principais na dimensão social são a condição humana e os meios utilizados para aumentar a qualidade de vida (VAN BELLEN, 2010).

A dimensão social do desenvolvimento tem incluído discussões, como o acesso a uma nutrição adequada e um sistema de saúde que permite a longevidade, o acesso à educação básica, que é necessária para a vida produtiva, e o acesso à renda, capaz de prover um padrão de vida decente. Essa dimensão tem sido avaliada amplamente pelo Índice de Desenvolvimento Humano (IDH), um sistema de indicadores desenvolvido em 1990 pelo Programa das Nações Unidas para o Desenvolvimento (SIEDENBERG, 2003). O IDH avalia questões humanas como mortalidade e educação, mas Souza (1999) ressalta que essas variáveis são analisadas em razão da renda, atribuindo maior importância ao crescimento econômico. Além disso, o IDH reflete a condição média de uma dada população, sem destacar a parte daqueles que não têm os requisitos básicos de sobrevivência digna atendidos (VAN BELLEN, 2010).

Avaliar a qualidade de vida dos cidadãos também tem sido interesse da Organização para a Cooperação e Desenvolvimento Econômico (OECD, 2009). O desenvolvimento baseado na qualidade de vida, contudo, requer padrões de produção e consumo mais intensos, pressionando a capacidade de o meio ambiente fornecer os recursos necessários. Nesse sentido, Stiglitz, Sem e Fitoussi (2009) defendem que o bem-estar dos cidadãos deve ser considerado em uma perspectiva de sustentabilidade, e não de resultados econômicos.

O crescimento populacional é um tema que tem estado nos debates sobre desenvolvimento sustentável com base no posicionamento pessimista de Malthus no século 18, afirmando que o crescimento da população seria maior do que capacidade de a terra fornecer alimento, o que, por sua vez, provocaria uma intensa distribuição desigual e crises sociais (KENNEDY, 1993). Novas oportunidades para a sociedade surgiram, porém, por meio da emigração, da revolução agrícola e da revolução industrial. Segundo 
Kennedy (1993), o risco de existência das condições de vida no planeta está associado ao crescimento da população e das atividades econômicas, pois não haveria condições de manter os padrões de nível de consumo conforme as tendências de crescimento populacional. O planeta tem sofrido degradação tanto dos países mais pobres, em razão do crescimento populacional exagerado, quanto dos países mais ricos em virtude da industrialização (KENNEDY, 1993).

As crises desencadeadas na dimensão ambiental têm sido debatidas desde a Conferência de Estocolmo em 1972 (SACHS, 2007). A economia ecológica considera que o desenvolvimento socioeconômico e o bem-estar humano dependem da capacidade de carga do planeta e das funções dos ecossistemas (LEUKHARDT; ALLEN, 2013). Segundo Sachs (1993), o desenvolvimento sustentável requer um planejamento que contemple a dimensão ecológica, entre outras, que se refere à prevenção de danos ao meio ambiente. A principal preocupação na dimensão ambiental, reforçada por Van Bellen (2010), é o impacto das atividades humanas sobre o meio ambiente. Nas abordagens multidimensionais do desenvolvimento sustentável, o capital natural apresentado na forma das funções dos ecossistemas e o capital produzido pelos humanos, são elementos compensatório na equação da qualidade do desenvolvimento, uma vez que os custos da deterioração ambiental podem ser mensurados em unidades monetárias e compensados pelos benefícios do capital produzido pelos indivíduos (PEARCE; ATKINSON, 1993; RENNINGS; WIGGERING, 1997). Conforme as crises causadas pelas mudanças climáticas vão ganhando formas mais evidentes, o imperativo ecológico vai atuar com uma força cada vez maior, sendo tais crises uma confirmação da incapacidade dos mercados em perceber e lidar com a dimensão ambiental do desenvolvimento (SACHS, 2007).

Na perspectiva preservacionista de sustentabilidade forte, a compensação entre as formas de capital, natural e produzido por humanos, não é aceita, pressupondo a manutenção dos ecossistemas intactos. Nessa abordagem, a estabilidade, resiliência e função ecológica dos ecossistemas são protegidas por meio da sua avaliação em unidades físicas, rejeitando as dinâmicas de valoração monetária das funções ambientais (RENNINGS; WIGGERING, 1997). A salvaguarda das funções ambientais identifica qualquer depreciação no capital natural como um sinal de insustentabilidade e proporciona um nível de produção que pode ser mantido indefinidamente sem ameaçar as condições de vida das futuras gerações (HUETING; REIJNDERS, 2004; PEARCE; ATKINSON, 1993). A dimensão ambiental do desenvolvimento sustentável é comumente representada pela Pegada Ecológica, que é um sistema de avaliação lançado na segunda metade da década de 90 do século 20 para compreender o nível de impacto humano sobre o meio ambiente. A Pegada Ecológica é usada para estimar a área total de terra requerida para sustentar o padrão de vida e consumo de uma população, representando a proporção da capacidade de carga do sistema total, que é apropriada por uma determinada população em decorrência do seu padrão de consumo (REES, 1992). A Pegada Ecológica tem a capacidade educativa de revelar que o ecossistema terrestre não é capaz de sustentar o nível de atividade econômica e de consumo de matéria-prima indefinidamente, apontando para a necessidade de aproveitamento dos recursos naturais dentro da capacidade de carga do sistema (VAN BELLEN, 2006). 


\section{A TRAJETÓRIA RECENTE DA COTONICULTURA CONVENCIONAL}

Uma característica da trajetória da cotonicultura é sua orientação para o comércio internacional, que foi estabelecida historicamente. A exportação de algodão nacional foi restringida até meados dos anos 70 pela Carteira de Comércio Exterior (Cacex), que estabelecia o regime de cota e fazia o controle da oferta de forma que apenas o excedente do consumo nacional de algodão poderia ser exportado (CRUZ; MAIA, 2008). Na segunda metade da década de 80 as restrições do governo para exportações de algodão, as infestações de pragas nas regiões de cultivo e a perda da competitividade em relação ao algodão importado, causaram um expressivo declínio da produção de algodão no Brasil. Isto se deu até o final da década de 90, enquanto as importações cresceram nesse período (FERREIRA-FILHO; ALVES; VILLAR, 2009). Durante a década de 90 houve uma redução da produção e da exportação de algodão nacional, como efeito da intensificação da abertura da economia, reduzindo as alíquotas de importação e estimulando-a, ao invés de estimular a produção nacional para atender às demandas das indústrias (CRUZ; MAIA, 2008).

Em resposta ao declínio da cultura de algodão brasileiro, na década de 90 os produtores receberam incentivos da Embrapa e do Centro Nacional de Pesquisa do Algodão (CNPA), que intensificaram a pesquisa agropecuária da cultura (CRUZ; MAIA, 2008). Além disso, Cruz e Maia (2008) ressaltam o aumento de intervenção governamental na comercialização do algodão por meio de instrumentos como o Planejamento Estratégico Participativo (PEP), Programa de Garantia da Atividade Agropecuária (Proagro) e Programa Nacional de Fortalecimento da Agricultura Familiar (Pronaf) para incentivar o crescimento da produção e das exportações, assim como a redução das importações.

Ao final da década de 90 a cotonicultura foi direcionada para as áreas do cerrado por meio de grandes investimentos no cultivo de algodão como uma cultura de rotatividade pelos produtores de soja, possibilitando a recuperação da produção nacional e diminuindo a necessidade de importações (CRUZ; MAIA, 2008). A redução das importações e retomada das exportações de algodão brasileiro foi favorecida pelo aumento da produção (FERREIRA-FILHO; ALVES; VILLAR, 2009). Nesse sentido, Ferreira-Filho, Alves e Villar (2009) apontam para a necessidade de investir em novas tecnologias para reduzir custos na produção de algodão e melhorar os resultados da atividade. Nessa perspectiva, os sistemas agroecológicos de cotonicultura são uma opção capaz de reduzir os custos na produção, uma vez que dispensam investimentos em insumos sintéticos.

Nas últimas décadas houve um crescimento intenso na produtividade dos cultivos localizados na nova fronteira agrícola do país (AGUIAR; LIMA-FILHO; TORRES-FILHO, 2013). A produção de algodão nacional já alcança os maiores níveis de produtividade do mundo, sendo o controle e a redução dos custos um meio de manter a competitividade e a renda para os produtores brasileiros. Nesse sentido, merece destaque a proporção dos gastos com defensivos químicos nos custos totais da cotonicultura nacional, os quais representam aproximadamente 37\% (FERREIRA-FILHO; ALVES; VILLAR, 2009).

A cotonicultura no cerrado desenvolveu-se com a utilização intensiva de mecanização, de novas técnicas relacionadas à agricultura convencional e da regularidade dos períodos de chuva, que, por sua vez, levaram à expansão da produtividade nessa região, diferentemente da tradicional cultura de algodão no Nordeste, que entrou em 
crise em razão da infestação do bicudo e das variações climáticas (CRUZ; MAIA, 2008). O aumento da produtividade, no final da década de 90 , foi protagonizado por um novo paradigma da cotonicultura nacional no Centro-Oeste do país, praticada em grandes extensões, intensiva em capital e moderna tecnologicamente, em substituição ao padrão produtivo tradicional intensivo em mão de obra e tecnologicamente atrasado (FERREIRA-FILHO; ALVES; VILLAR, 2009). Esse paradigma tem dado suporte e promovido o desenvolvimento nacional, especialmente na sua dimensão econômica. Adicionalmente, as populações rurais da cotonicultura convencional são mais submetidas às condições já estruturadas do seu agronegócio. Essas condições são manifestadas nas relações empresariais de trabalho que os agricultores estabelecem com as empresas agroindustriais da cotonicultura convencional no cerrado.

Com relação ao meio ambiente, o sistema de cotonicultura convencional assume o papel de usuário de serviços ambientais, sobretudo das chuvas em períodos regulares no cerrado (CRUZ; MAIA, 2008), e não de um sistema gerador de serviços e benefícios ecológicos. No cerrado, a biodiversidade é reduzida em decorrência da cotonicultura convencional, pois ela utiliza áreas de cultivo em monocultura nos mais de 320 mil hectares (CONAB, 2016).

A cotonicultura convencional no cerrado está fundamentada na lógica de crescimento econômico, com resultados concentrados em empresas com alto nível de capitalização e produtividade. Esse nível de produtividade na cotonicultura convencional no cerrado está associado aos investimentos para evitar perdas com a aplicação de agrotóxicos, que representam mais de um terço $(1 / 3)$ dos custos totais da produção (FERREIRA-FILHO; ALVES; VILLAR, 2009).

Quando se trata da obtenção de resultados econômicos, os sistemas de cotonicultura convencional e orgânico têm provocado incidências distintas relacionadas ao tipo de economia praticada, aos níveis de produtividade e renda, bem como à composição dos custos totais dos cultivos. Os sistemas de cotonicultura convencional e orgânico também promovem distintos bens socioculturais e resultados ecológicos.

\section{A TRAJETÓRIA RECENTE DA COTONICULTURA ORGÂNICA}

A cotonicultura orgânica na caatinga está orientada para uma economia solidária, com maior capacidade distributiva, pela sua forma de inserção em circuitos de comércio justo (FARIA; PEREIRA, 2012). A inserção nesses circuitos comerciais garante ao produtor de algodão orgânico uma remuneração por quilo que pode alcançar o dobro da obtida com a venda de algodão convencional, embora as empresas agroindustriais do convencional tenham uma produtividade média que representa mais que o triplo da produtividade obtida na cotonicultura orgânica. Os custos com agrotóxicos são eliminados na cotonicultura orgânica na caatinga, mas faltam informações sistematizadas sobre os seus custos totais. Nesse sentido, a cotonicultura orgânica possui custos altos para os agricultores quando é certificada por auditoria e quando tem perdas decorrentes da variabilidade ao clima e às pragas, além de ter resultados ainda inferiores, tendo em vista a menor média de produtividade em comparação ao convencional. Em virtude, porém, do fato de a cotonicultura orgânica ser realizada em conjunto com outros culti- 
vos, com resultado econômico de maneira consorciada na mesma área, a comparação da sua produtividade com o sistema convencional precisa ser ponderada, uma vez que, neste, toda a área produtiva é dedicada apenas ao cultivo do algodão.

O mercado de algodão orgânico desenvolveu-se recentemente e, por ainda ser um produto escasso, os produtores têm conseguido rendimentos que representam o dobro do que conseguiriam com o algodão convencional. Em meio ao crescente mercado de produtos orgânicos, a produção deste algodão surgiu no Brasil na década de 90 por uma iniciativa da ONG Esplar, que buscava uma solução de base ecológica para enfrentar a praga do bicudo na cotonicultura, introduzindo práticas de conservação dos solos, o uso do cultivar CNPA 4M (algodão com maior produtividade) e a incorporação da leucena aos consórcios tradicionais de algodão com milho e feijão (BELTRÃO et al., 2010). Desde então a produção de algodão orgânico cultivado no semiárido cearense pela Associação de Desenvolvimento Educacional e Cultural (Adec) tem beneficiado 320 famílias (BOSSLE et al., 2012). Beltrão et al. (2010) afirmam que os produtores de vários municípios foram estimulados a retomar a cotonicultura, utilizando bases ecológicas pelos resultados obtidos na iniciativa do Esplar em termos de recuperação e manutenção dos solos, do estado nutricional das plantas e do aumento dos rendimentos médios.

A produção de algodão da Adec começou a ser comercializada para duas cadeias produtivas de comércio justo em 2003, sendo uma empresa francesa chamada "Tênis" e uma rede de cooperativas brasileiras chamada "Justa Trama", que se tornaram os principais compradores de algodão orgânico produzido no Ceará (BOSSLE et al., 2012). A participação nas cadeias de comércio justo promove o desenvolvimento de consciência ecológica, educação ambiental e técnicas sustentáveis de produção pelos produtores de algodão orgânico associados à Adec, em uma dinâmica de economia solidária (FARIA; PEREIRA, 2012).

Segundo Faria e Pereira (2012), as atividades da Adec promovem a construção de relações de confiança com os agricultores, necessárias para a dinâmica de uma economia solidária com base na satisfação deles em relação ao cumprimento dos prazos de pagamento, melhorias alcançadas na qualidade de vida, assistências técnicas recebidas e garantias de comercialização. Em 2008, a Esplar e a Embrapa Algodão estabeleceram uma parceria com o Projeto Dom Helder Camara (PDHC), para ter suporte na produção de algodão com base agroecológica nos territórios de suas ações, agregando uma participação crescente, a qual somou aproximadamente mil famílias de agricultores em 2013. O PDHC é uma organização do governo federal que tem utilizado a agroecologia como base para ações de desenvolvimento rural sustentável na região semiárida do Nordeste brasileiro, com o objetivo de criar referências de políticas públicas para erradicação da pobreza (JALFIM et al., 2013).

A região semiárida nordestina apresenta solo e clima adequados ao cultivo de algodão orgânico, além da tradição com a cotonicultura e a presença de estrutura de beneficiamento do algodão, que tornam essa região um ambiente propício para a cotonicultura orgânica (BELTRÃO et al., 2010). Beltrão et al. (2010) afirmam que a cotonicultura orgânica na caatinga tem despertado interesse dos agricultores, com o surgimento de cultivares de algodão mais produtivos e coloridos, além do surgimento de novos mercados consumidores que buscam um posicionamento ecologicamente sustentável.O modelo de comércio justo prevê o pagamento de um prêmio aos produtores 
no fim da colheita. Isto tem sido utilizado pela Adec para promover benefícios coletivos aos agricultores, incluindo o custeio das certificações necessárias. O modelo de comércio justo em que a Adec se inseriu, inclui a fixação de contratos de compra antecipada, permitindo aos produtores saber o valor que será recebido nos próximos anos, antes mesmo de iniciar o cultivo (BOSSLE et al., 2012). O valor do algodão orgânico recebido pelos produtores que fazem parte das cadeias de comércio justo representa o dobro do valor oferecido no mercado comum, sendo a produção de algodão orgânico a principal atividade no rendimento destes produtores (FARIA; PEREIRA, 2012). Na cotonicultura orgânica na caatinga, as populações rurais possuem maior autonomia social em decorrência do engajamento em processos participativos de certificações e em uma forma de economia solidária baseada na autogestão (ANDRADA; SATO, 2014).

A cotonicultura orgânica convive com as condições climáticas e do solo da caatinga nordestina, sendo um sistema produtivo capaz de promover a biodiversidade e gerar benefícios ecológicos no bioma caatinga, pois é realizada em consórcio com outros cultivos locais, respeitando os princípios da agroecologia.

De acordo com Assis (2006), os sistemas de agricultura orgânica proporcionam bens econômicos, socioculturais e ecológicos que dão base para um processo de desenvolvimento sustentável no meio rural. De acordo com as discussões apresentadas nesta seção, foi elaborada a seguinte proposição: os locais que se dedicam à cotonicultura orgânica obtêm melhores resultados econômicos, socioculturais e ecológicos na evolução dos indicadores de desenvolvimento do que aqueles dedicados à cotonicultura convencional.

\section{METODOLOGIA}

O objetivo deste artigo foi comparar os municípios nordestinos dedicados à cotonicultura convencional e à orgânica a partir das mudanças nos seus indicadores de desenvolvimento no período dos anos 2000 a 2010. Nesse sentido, o presente estudo é de natureza descritiva, pois relata um fenômeno (COOPER; SCHINDLER, 2003), e adota uma abordagem quantitativa na coleta e análise dos dados.

Esta pesquisa teve os municípios nordestinos dedicados à cotonicultura convencional e à orgânica como objeto de estudo. Para realizar a investigação, foram coletados dados de uma amostra constituída de maneira intencional pelos municípios com a cotonicultura mais expressiva em ambos os paradigmas. Os municípios dedicados à cotonicultura convencional foram selecionados considerando os maiores exportadores de algodão no período estudado de acordo com os registros do Ministério do Desenvolvimento, Indústria e Comércio Exterior (MDIC, 2016). Os municípios dedicados à cotonicultura orgânica foram selecionados considerando as localizações das sedes dos Organismos Participativos de Avaliação da Conformidade Orgânica (OPACs) e os municípios com as maiores quantidades de produtores vinculados aos OPACs de acordo com o Cadastro Nacional de Produtores Orgânicos (MAPA, 2016). O Quadro 1 mostra o conjunto de municípios que forma a amostra. Cabe ressaltar que, embora não seja um município nordestino, Taguatinga foi incluído no estudo por ser parte da nova fronteira agrícola com uma cotonicultura significativa e estar localizado próximo à divisão com a Região Nordeste. 
No conjunto de municípios dedicados à cotonicultura convencional, esta atividade representou valores próximos de $11 \%$ do PIB total e $26 \%$ do PIB das atividades agropecuárias no ano de 2010. Em 2015, no entanto, essa representação declinou para $7 \%$ do PIB e $16 \%$ das atividades agropecuárias aproximadamente. Ao longo do período de 2010 a 2015, São Desidério (BA) merece destaque por ter as maiores representações dos valores produzidos pela cotonicultura no PIB total (52\% em 2010 e 32\% em 2015) e no PIB das atividades agropecuárias do município (80\% em 2010 e $48 \%$ em 2015). Por sua vez, no conjunto de municípios com incidências da cotonicultura orgânica, esta atividade possuiu representações inferiores a 1\% do PIB total e do PIB das atividades agropecuárias, tanto em 2010 quanto em 2015 (IBGE, 2017).

Quadro 1 - Municípios da amostra

\begin{tabular}{|l|l|}
\hline \multicolumn{1}{|c|}{ Convencional } & \multicolumn{1}{c|}{ Orgânico } \\
\hline Luís Eduardo Magalhães (BA) & São Raimundo Nonato (PI) \\
\hline Barreiras (BA) & Quixeramobim (CE) \\
\hline São Desidério (BA) & Nova Russas (CE) \\
\hline Correntina (BA) & Ouricuri (PE) \\
\hline Balsas (MA) & Apodi (RN) \\
\hline Tasso Fragoso (MA) & Afogados da Ingazeira (PE) \\
\hline Jaborandi (BA) & Quixadá (CE) \\
\hline Formosa do Rio Preto (BA) & Santa Cruz (PE) \\
\hline Uruçuí (PI) & Choró (CE) \\
\hline Sebastião Leal (PI) & Tamboril (CE) \\
\hline Bom Jesus (PI) & Monsenhor Tabosa (CE) \\
\hline Baixa Grande do Ribeiro (PI) & Catunda (CE) \\
\hline Taguatinga (TO) & Parnamirim (PE) \\
\hline
\end{tabular}

Fonte: Elaborado pelos autores.

Para esta pesquisa foram coletados dados secundários sobre: o PIB dos municípios nos setores da indústria, da agropecuária e de serviços; o IDH dos municípios e seus componentes de renda, educação e longevidade da população; e a quantidade de domicílios com bens duráveis, sendo eles rádio, televisão, máquina de lavar roupa, geladeira, microcomputador e automóvel. Os dados sobre o PIB e a quantidade de domicílios com bens duráveis foram coletados no banco de informações do IBGE-Cidades (IBGE, 2017), consultando os dados sobre o PIB municipal e o Censo Demográfico. Já os dados sobre o IDH foram coletados no Atlas de Desenvolvimento Humano do Brasil (PNUD, 2016). Este é um estudo longitudinal, pois os dados coletados descrevem os fenômenos investigados em diferentes momentos no tempo. Nesse sentido, foram coletados dados referentes aos anos 2000 e 2010.

Para o processo de análise, os dados coletados sobre cada município que compõe a amostra foram organizados para calcular as variações percentuais dos valores do ano 2010 em relação aos valores do ano 2000. Em seguida, foram obtidas as variações percentuais dos conjuntos de municípios dedicados à cotonicultura convencional e à orgânica, para realizar uma comparação direta entre os resultados desses conjuntos de municípios. Este estudo, portanto, adota uma abordagem comparativa na análise dos 
resultados. Além disso, também foram obtidos os índices de correlação e significância entre as variáveis do estudo, com o auxílio do software IBM SPSS Statistics 23, para identificar associações que caracterizam o desenvolvimento dos municípios no paradigma convencional e no orgânico. A seguir são apresentados os resultados do estudo.

\section{RESULTADOS E DISCUSSÕES}

Os dados estudados são parte de dois territórios distintos, sendo a cotonicultura convencional uma característica do território da fronteira agrícola no sudoeste nordestino, enquanto cotonicultura orgânica é uma característica do território semiárido nordestino (Figura 1). Assim, os resultados deste estudo destacam dados sobre o processo de desenvolvimento de dois territórios, que são baseados em sistemas distintos de produção agrícola na cotonicultura.

Figura 1 - Áreas de incidência da cotonicultura convencional e da orgânica no Nordeste

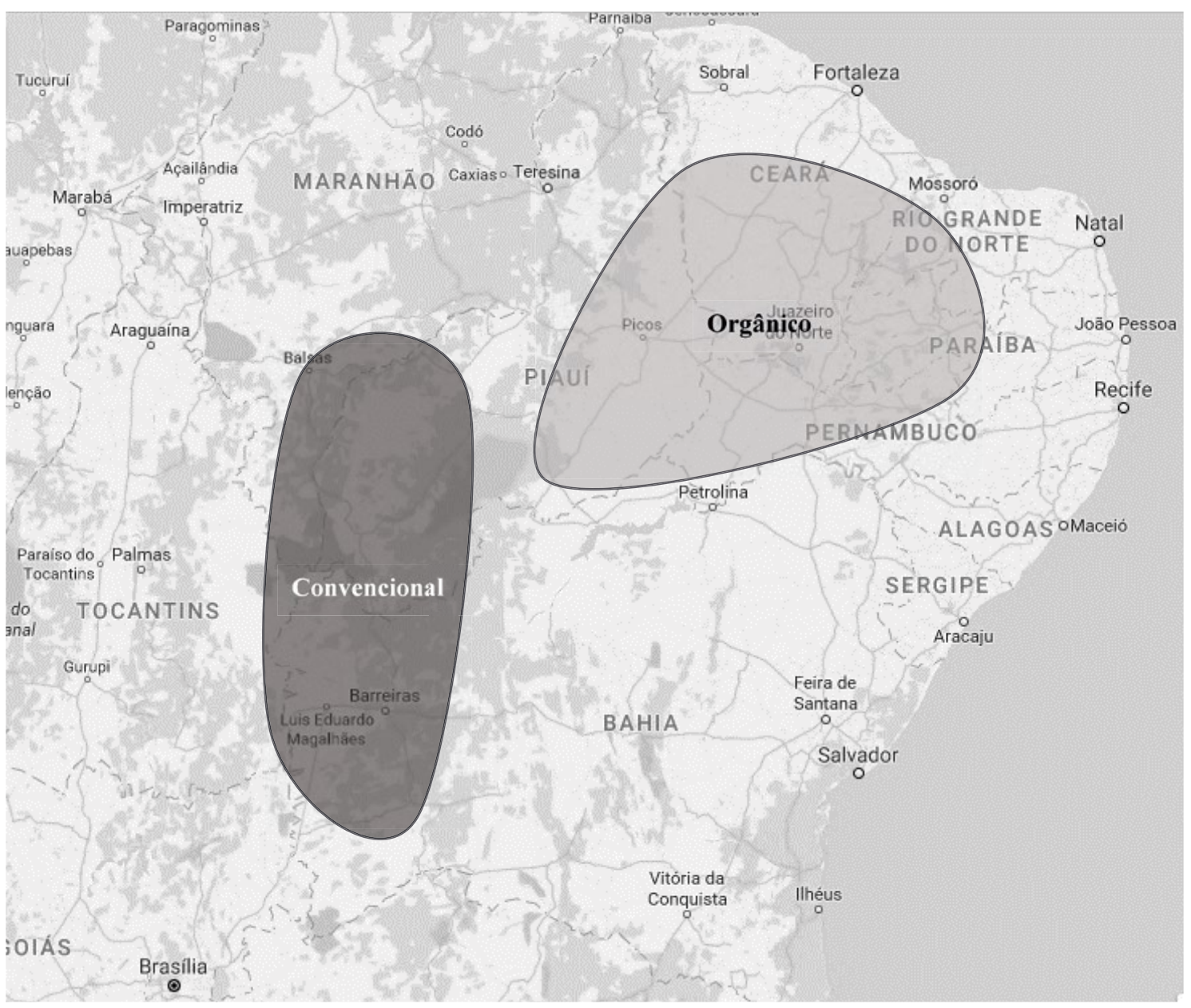

Fonte: Elaborada pelo autor.

Os municípios nordestinos mais próximos das áreas dedicadas à cotonicultura convencional formam um corredor no cerrado entre Uruçuí, no Piauí, e Jaborandi, na Bahia, abrigando agronegócios orientados à exportação de algodão e localizados na nova fronteira agrícola do país (AGUIAR; LIMA-FILHO; TORRES-JUNIOR, 2013). Com relação à cotonicultura orgânica, suas atividades têm implicações mais diretas em municípios localizados no semiárido nordestino, que é um ambiente propício para a cotonicul- 
tura orgânica, segundo Beltrão et al. (2010), principalmente nos Estados do Ceará, Rio Grande do Norte, Paraíba, Piauí e Pernambuco. Os aspectos de desenvolvimento desses territórios no período do ano 2000 a 2010 contextualizam as tendências com as quais os sistemas produtivos estudados podem estar alinhados ou não, pois tais paradigmas foram estabelecidos nos seus territórios nesse período. Inicialmente são apresentados os resultados sobre a dimensão econômica, tomando o crescimento do PIB no período 2000-2010. Em seguida, os resultados sobre a dimensão social são apresentados, analisando a evolução do IDH no mesmo período. Por fim, são apresentados os resultados sobre a dimensão ambiental, considerando os padrões de consumo de bens duráveis e seus impactos nos territórios estudados.

Ao comparar a evolução do PIB nos anos de 2000 e 2010, observa-se que os municípios na área da cotonicultura orgânica passaram por um crescimento econômico nesse período, com maior intensidade nas operações de serviços. $O$ desempenho nominal do PIB obtido na área composta pelos municípios dedicados à cotonicultura convencional, foi superior ao resultado obtido nos municípios da cotonicultura orgânica tanto em 2000 quanto em 2010. Nesse período, o setor econômico que obteve maior crescimento no conjunto dos municípios da cotonicultura convencional foi o setor industrial. Esse resultado corrobora o comentário de Ferreira-Filho, Alves e Villar (2009), que destacam a importância da modernização técnica e industrial no aumento da produtividade na cotonicultura nas áreas do cerrado. Por sua vez, o setor agropecuário obteve o menor crescimento econômico tanto nos municípios dedicados à cotonicultura convencional quanto nos dedicados à cotonicultura orgânica. O Quadro 2, a seguir, expõe indicadores de evolução do crescimento econômico dessas áreas no período analisado.

Quadro 2 - Evolução do PIB no período 2000-2010

\begin{tabular}{|l|c|c|c|c|c|c|}
\hline \multirow{2}{*}{ Indicador } & \multicolumn{3}{|c|}{ Convencional (x R\$ 1.000) } & \multicolumn{3}{c|}{ Orgânico (x R\$ 1.000) } \\
\cline { 2 - 7 } & $\mathbf{2 0 0 0}$ & $\mathbf{2 0 1 0}$ & $\mathbf{\%}$ & $\mathbf{2 0 0 0}$ & $\mathbf{2 0 1 0}$ & $\mathbf{\%}$ \\
\hline \%PIB-Agropecuária & $680.291,00$ & $2.223 .890,00$ & $227 \%$ & $110.662,00$ & $176.235,00$ & $59 \%$ \\
\hline \%PIB-Indústria & $245.781,00$ & $1.322 .748,00$ & $438 \%$ & $155.113,00$ & $502.725,00$ & $224 \%$ \\
\hline \%PIB-Serviços & $955.800,00$ & $3.988 .125,00$ & $317 \%$ & $452.950,00$ & $1.662 .196,00$ & $267 \%$ \\
\hline \%PIB & $2.034 .880,00$ & $8.323 .086,00$ & $309 \%$ & $751.958,00$ & $2.513 .073,00$ & $234 \%$ \\
\hline \%PIB per capita & 4,64 & 18,97 & $309 \%$ & 1,74 & 5,15 & $196 \%$ \\
\hline \%PIB per capita rural & 5,61 & 20,74 & $270 \%$ & 0,62 & 0,99 & $61 \%$ \\
\hline
\end{tabular}

Fonte: IBGE (2017).

Considerando a variação ao longo dos dez anos, Sebastião Leal (PI) foi o município onde houve o crescimento do PIB mais acentuado, que passou de 6,6 milhões de reais em 2000 para 67,4 milhões de reais em 2010, representando um crescimento de 908\%. Na evolução do PIB de Sebastião Leal, o setor industrial teve o maior crescimento: $5.146 \%$ do resultado obtido no ano 2000 . Sebastião Leal também teve o maior crescimento do PIB do setor agropecuário, que aumentou em $612 \%$ no período estudado, e do setor de serviços, que aumentou em 636\% do resultado do ano 2000. 
Os menores desempenhos do PIB no período estudado estão relacionados aos municípios dedicados à cotonicultura orgânica. Compreendendo que a cotonicultura orgânica promove a ideia de sustentabilidade, esse resultado corrobora o comentário de Leukhardt e Allen (2013), de que os objetivos ambientais parecem ser incoerentes ao empenho no aumento do PIB. Entre os municípios dedicados à cotonicultura orgânica, 0 de Apodi (RN) destaca-se pela pelo menor crescimento do PIB em $137 \%$ do resultado do ano 2000. Esse resultado do PIB do município de Apodi é decorrente do menor crescimento do setor industrial em $56 \%$ no período estudado, sendo o menor resultado desse setor de atividade no conjunto dos municípios analisados. Os menores resultados dos setores de atividade agropecuária e industrial foram, respectivamente, um crescimento de 3\% em Monsenhor Tabosa (CE) e um crescimento de 133\% em Barreiras (BA).

Ao compreender que, em uma escala apropriada, a alocação eficiente dos recursos é um elemento importante na dimensão econômica do desenvolvimento (VAN BELLEN, 2010), o crescimento econômico torna-se uma medida mais adequada quando é relativizada pela população que é atendida por ele, ou seja, o PIB per capita. Nesse sentido, o conjunto de municípios da cotonicultura orgânica obteve, em 2010, um crescimento de quase o dobrou do PIB per capita do ano 2000. O grupo dos municípios da cotonicultura convencional, contudo, triplicou o PIB per capita no mesmo período. Entre estes, Sebastião Leal destaca-se com o aumento de $839 \%$. A distinção entre os grupos de municípios dedicados à cotonicultura orgânica e convencional torna-se mais acentuada quando é observado o PIB per capita das atividades agropecuárias em relação à população rural. Nesse indicador, o conjunto de municípios da cotonicultura convencional obteve um aumento de $270 \%$, com destaque para o crescimento de $1.126 \%$ em Jaborandi (BA), enquanto o grupo de municípios da cotonicultura orgânica obteve um aumento de $61 \%$ apesar da diminuição de 5\% em São Raimundo Nonato (PI).

Além das análises sobre o PIB e o PIB per capita, a dimensão econômica do desenvolvimento ainda pode ser indicada pela renda da população. A renda da população é um componente do IDH que teve uma evolução mais acentuada no conjunto de municípios da cotonicultura orgânica. Esse resultado é coerente ao comentário de Faria e Pereira (2012), de que a inserção nos circuitos de comércio justo garante ao produtor de algodão orgânico uma renda que pode alcançar o dobro da obtida com o algodão convencional. Quando os municípios são analisados de maneira isolada, porém, esse indicador obteve maior evolução no município dedicado à cotonicultura convencional de Jaborandi (BA), com um aumento de $32 \%$. A menor evolução da renda da população foi obtida em Formosa do Rio Preto (BA), que também é um município dedicado à cotonicultura convencional, com um aumento de apenas 1\% no período dos anos 2000 a 2010.

Quando se trata do Índice de Desenvolvimento Humano (IDH), o conjunto de municípios analisados, dedicados tanto à cotonicultura convencional quanto à orgânica, passa por uma evolução na longevidade, na renda e, com maior intensidade, na educação da população no período dos anos 2000 a 2010. Algumas diferenças nessas trajetórias, contudo, podem ser observadas. O Quadro 3 expõe os indicadores de evolução sobre o desenvolvimento humano desses municípios no período analisado. 
Quadro 3 - Evolução do IDH no período 2000-2010

\begin{tabular}{|l|c|c|c|c|c|c|}
\hline \multirow{2}{*}{\multicolumn{1}{c|}{ Indicador }} & \multicolumn{3}{|c|}{ Convencional } & \multicolumn{3}{c|}{ Orgânico } \\
\cline { 2 - 7 } & $\mathbf{2 0 0 0}$ & $\mathbf{2 0 1 0}$ & $\mathbf{\%}$ & $\mathbf{2 0 0 0}$ & $\mathbf{2 0 1 0}$ & $\mathbf{\%}$ \\
\hline \%IDH-Renda & 0,529 & 0,612 & $16 \%$ & 0,482 & 0,569 & $18 \%$ \\
\hline \%IDH-Educação & 0,257 & 0,524 & $104 \%$ & 0,270 & 0,532 & $97 \%$ \\
\hline \%IDH-Longevidade & 0,678 & 0,785 & $16 \%$ & 0,696 & 0,767 & $10 \%$ \\
\hline \%IDH & 0,449 & 0,630 & $40 \%$ & 0,446 & 0,614 & $37 \%$ \\
\hline
\end{tabular}

Fonte: IBGE (2017).

Nesse período analisado, o IDH do conjunto de municípios dedicados à cotonicultura convencional obteve uma evolução maior do que o conjunto de municípios da cotonicultura orgânica, correspondente a três pontos percentuais. Nesse sentido, o município de Jaborandi (BA) destaca-se com a maior evolução do IDH no conjunto dos municípios analisados, com um aumento de 64\% em 2010 quando comparado ao seu IDH no ano 2000. Por sua vez, o município de Quixadá (CE) destaca-se por ter obtido a menor evolução do IDH no período analisado, que corresponde a um aumento de $26 \%$.

A educação da população é um componente do IDH que teve uma evolução mais acentuada no conjunto de municípios da cotonicultura convencional, muito embora, isoladamente, o município de Tasso Fragoso (MA) tenha obtido a menor evolução nesse indicador, com um aumento de 59\%. Isoladamente, a maior evolução na educação da população é indicada no município dedicado à cotonicultura orgânica de Santa Cruz (PE), com um aumento de $215 \%$.

A longevidade da população também é um componente do IDH que teve uma evolução mais acentuada nos municípios da cotonicultura convencional, com maior aumento nos municípios de Tasso Fragoso (MA) e Baixa Grande do Ribeiro (PI), sendo 21\% maior em 2010 em relação ao indicado no ano 2000 para ambos. Os menores aumentos na longevidade da população foram obtidos com um aumento de $4 \%$ nos municípios de Apodi (RN), Quixadá (CE) e Catunda (CE).Na ausência de dados precisos sobre o nível de pressão que os municípios impõem ao meio ambiente, o aspecto de desenvolvimento, associado à dimensão ambiental, é analisado considerando a população do município e a quantidade de domicílios com determinados bens duráveis, permitindo avaliar os padrões de consumo. Essa forma de avaliar a dimensão ambiental do desenvolvimento está alinhada às contribuições de Rees (1992), que alerta para a capacidade de carga do planeta em razão do padrão de vida e consumo de uma população, e de Kennedy (1993), que destaca o crescimento populacional como um importante fator que põe em risco as condições de vida no planeta. O Quadro 4 expõe indicadores de evolução do crescimento populacional e do padrão de consumo da população nos conjuntos de municípios analisados. 
Quadro 4 - Evolução de domicílios com bens duráveis no período 2000-2010

\begin{tabular}{|l|c|c|c|c|c|c|}
\hline \multirow{2}{*}{\multicolumn{1}{c|}{ Indicador }} & \multicolumn{3}{|c|}{ Convencional } & \multicolumn{3}{c|}{ Orgânico } \\
\cline { 2 - 7 } & $\mathbf{2 0 0 0}$ & $\mathbf{2 0 1 0}$ & $\mathbf{\%}$ & $\mathbf{2 0 0 0}$ & $\mathbf{2 0 1 0}$ & $\%$ \\
\hline \% População & 334532 & 451726 & $35 \%$ & 401864 & 448771 & $11 \%$ \\
\hline \% Geladeira & 46258 & 105074 & $127 \%$ & 48340 & 103711 & $115 \%$ \\
\hline \% Máq. Lavar Roupa & 7568 & 25445 & $236 \%$ & 3178 & 12729 & $301 \%$ \\
\hline \% Rádio & 55803 & 76969 & $38 \%$ & 79245 & 99337 & $25 \%$ \\
\hline \% Televisão & 51570 & 109328 & $112 \%$ & 68193 & 113389 & $66 \%$ \\
\hline \% Microcomputador & 2818 & 27004 & $858 \%$ & 1256 & 15500 & $1134 \%$ \\
\hline \% Automóvel & 12572 & 30842 & $145 \%$ & 11119 & 17078 & $54 \%$ \\
\hline \% Média Dom. com bens & 29432 & 62444 & $112 \%$ & 35222 & 60291 & $71 \%$ \\
\hline
\end{tabular}

Fonte: IBGE (2017).

No período dos anos 2000 a 2010, o crescimento populacional, e a correspondente pressão dos padrões de consumo no meio ambiente, foi mais intenso no conjunto de municípios dedicados à cotonicultura convencional. O maior crescimento populacional aconteceu no município de Luís Eduardo Magalhães (BA), que aumentou em $220 \%$ no período analisado. Embora o conjunto de municípios da cotonicultura orgânica tenha obtido um crescimento populacional menor, foi o município de Jaborandi (BA), dedicado à cotonicultura convencional, que teve o menor resultado, com uma diminuição de $13 \%$ na sua população no período analisado.

Ao analisar a evolução dos padrões de consumo nos municípios estudados, os bens duráveis considerados foram: rádio, televisão, máquina de lavar roupa, geladeira, microcomputador e automóvel. No conjunto de municípios analisados, a quantidade de domicílios com microcomputadores teve o maior crescimento no período dos anos 2000 a 2010, enquanto o menor crescimento foi na quantidade de domicílios com rádio. Dos seis bens duráveis analisados, houve menor aumento na quantidade de domicílios com máquinas de lavar roupa e microcomputadores nos municípios da cotonicultura convencional. Desses municípios, Taguatinga (TO) destaca-se com os menores aumentos desses bens duráveis, embora tenha crescido os números de domicílios com máquinas de lavar roupa em $92 \%$ e de microcomputadores em $701 \%$ no período analisado.

O conjunto de municípios dedicados à cotonicultura orgânica obteve menor crescimento na quantidade de domicílios com geladeiras, rádios, televisões e automóveis no período dos anos 2000 a 2010. Nesse sentido, o município de Afogados da Ingazeira (PE) destaca-se pelo menor aumento no número de domicílios com geladeiras e televisões, sendo $84 \%$ e $38 \%$ respectivamente. O menor aumento no número de domićlios com automóveis foi obtido no município de Tamboril (CE), onde houve uma diminuição de $36 \%$ no período analisado. O município de Tamboril (CE) também se destaca por ser onde houve o menor crescimento médio de domicílios com o conjunto de bens duráveis analisados, que foi de $51 \%$. Por sua vez, o maior crescimento médio desses domicílios, de $172 \%$, aconteceu no município da cotonicultura convencional de Tasso Fragoso (MA).

De acordo com os resultados obtidos, a população do conjunto de municípios dedicados à cotonicultura orgânica teve uma elevação no padrão de consumo dos bens analisados menor do que a população dos municípios da cotonicultura convencional. 
Essa comparação entre os padrões de consumo indica que, no geral, a população residente nos municípios da cotonicultura convencional impõe um nível maior de pressão ao meio ambiente do que a população residente nos municípios da cotonicultura orgânica.

É importante ressaltar que o comportamento consumista não é entendido neste estudo em razão das diferenças de poder aquisitivo da população, de forma que os mais pobres consumiriam menos e, por sua vez, a pobreza seria um fator positivo para a dimensão ambiental do desenvolvimento. De outra forma, o comportamento consumista, sobretudo o hiperconsumo irresponsável, é entendido como um fator cultural dos estilos de vida da modernidade, que ameaçam os valores ecológicos (LIPOVETSKY; SERROY, 2015). Assim, uma reflexão crítica do comportamento orienta a mudança do padrão de consumo, que pode acontecer em qualquer estrato da população, independentemente do nível de renda. Nesse sentido, a sociedade atual está tornando possível identificar grupos compostos por pessoas com alta renda e baixo consumo, em razão da internalização de uma reflexão crítica sobre o estilo de vida, e grupos compostos por pessoas com baixa renda e alto consumo, pelos estímulos das propagandas e as facilidades do mercado.

Além da análise do padrão de consumo de bens duráveis, outros fatores são particularmente importantes na compreensão do processo de desenvolvimento no contexto investigado, como a extensão e a qualidade do uso da terra. O Quadro 5 mostra as áreas de terras utilizadas para o cultivo de algodão e a estimativa de volume de agrotóxicos em ambos os grupos de municípios estudados.

Quadro 5 - Evolução do uso da terra no período 2000-2015

\begin{tabular}{|c|c|c|c|c|c|c|c|c|c|c|}
\hline & \multicolumn{4}{|c|}{ Convencional } & \multicolumn{5}{|c|}{ Orgânico } \\
\cline { 2 - 11 } Indicador & 2000 & 2010 & $\%$ & 2015 & $\%$ & 2000 & 2010 & $\%$ & 2015 & $\%$ \\
\hline \%Área (ha) & 35.191 & 238.131 & $576,7 \%$ & 301.367 & $26,6 \%$ & 21.540 & 273 & $-98,7 \%$ & 270 & $-1,1 \%$ \\
\hline Agrot (1.000L) & 845 & 5.715 & $576,7 \%$ & 7.233 & $26,6 \%$ & 516 & 0 & $-100 \%$ & 0 & $0 \%$ \\
\hline
\end{tabular}
Fonte: IBGE (2017); PIGNATI; OLIVEIRA; SILVA (2014).

Percebe-se que houve um aumento de $576 \%$ na área de cultivo nos municípios da cotonicultura convencional no período de 2000 a 2010, e um aumento de $26 \%$ no período de 2010 a 2015. Por se tratar do cultivo convencional, em monocultura e com o uso de defensivos químicos, estima-se o uso de 7.233 mil litros de agrotóxicos em 2015 , considerando uma média de 24 litros por hectare nos cultivos anuais de algodão (PIGNATI; OLIVEIRA; SILVA, 2014). Com relação ao conjunto de municípios da cotonicultura orgânica, houve uma redução de $98 \%$ na área de terra usada no período de 2000 a 2010, e uma redução posterior de $1 \%$ entre 2010 e 2015. A cotonicultura orgânica dispensa o uso de defensivos químicos, podendo-se estimar que, após o ano 2000 - quando os sistemas orgânicos ainda não estavam estruturados - não houve o uso de quantidade significativa de agrotóxicos, em comparação aos padrões dos sistemas agroindustriais. Na dimensão ambiental, portanto, esses resultados apontam uma tendência mais favorável no uso da terra no conjunto dos municípios da cotonicultura orgânica. 
Para identificar um resultado total sobre as trajetórias de desenvolvimento nos municípios analisados, os resultados obtidos sobre o PIB per capita, o IDH e o consumo de bens duráveis foram sintetizados utilizando a seguinte fórmula (1):

(1) $E v D S=\frac{(E v P I B+E v I D H)-2 E v B D}{4}$

Onde: EvDS é o percentual de evolução de um município para o desenvolvimento sustentável em um período; EvPIB é o percentual de evolução do PIB per capita; EvIDH é o percentual de evolução do IDH; e EvBD é o percentual de evolução do consumo de bens duráveis. $\mathrm{O}$ índice EvDS considera a propriedade compensatória entre as dimensões econômica, social e ambiental no entendimento do desenvolvimento sustentável (PEARCE; ATKINSON, 1993; RENNINGS; WIGGERING, 1997). Além disso, também é considerado o equilíbrio entre as dimensões antropocêntricas (econômica e social) e ecocêntrica (ambiental) (AUGUSTIN; ALMEIDA, 2011), sendo atribuído um peso duplo ao resultado de EvBD. Os resultados para esses indicadores são mostrados no Quadro 6.

Quadro 6 - Evolução das dimensões do desenvolvimento no período 2000-2010

\begin{tabular}{|c|c|c|}
\hline Indicador & Convencional & Orgânico \\
\hline EvPIB & $309 \%$ & $196 \%$ \\
\hline EvIDH & $40 \%$ & $37 \%$ \\
\hline EvBD & $112 \%$ & $71 \%$ \\
\hline EvDS & $31 \%$ & $23 \%$ \\
\hline
\end{tabular}

Fonte: Elaborado pelos autores.

Por meio do índice construído, o conjunto de municípios dedicados à cotonicultura convencional obteve uma evolução de $31 \%$ em sua orientação para um desenvolvimento sustentável, enquanto o conjunto de municípios dedicados à cotonicultura orgânica obteve uma evolução de $23 \%$ no período dos anos 2000 a 2010 . Entre os municípios analisados, Uruçuí (PI) e Sebastião Leal (PI) destacam-se com as maiores evoluções orientadas para um desenvolvimento sustentável, com os resultados de $132 \%$ e $129 \%$ respectivamente. Por sua vez, a evolução que mais se afasta da orientação para um desenvolvimento sustentável foi observada no município de São Desidério (BA), que obteve um resultado negativo em $48 \%$. Também foi calculado o desvio padrão (DP) do EvDS para os dois grupos de municípios investigados, e observa-se como resultado que existe uma dispersão maior dos resultados entre os municípios dedicados à cotonicultura convencional $(D P=0,69)$ do que entre aqueles da cotonicultura orgânica $(D P=0,11)$. Embora, portanto, o conjunto de municípios dedicados à cotonicultura convencional tenha obtido uma evolução em orientação para um desenvolvimento sustentável de maneira mais forte, este mesmo grupo é composto por municípios com resultados muito distintos, como Uruçuí e São Desidério, mencionados anteriormente.

A análise de correlações entre os dados mostrou que algumas variáveis não possuem forte associação com as demais, como os indicadores de renda e longevidade, que compõem o IDH, bem como a quantidade de domicílios com máquinas de lavar roupa, microcomputadores e automóveis, que compõem os padrões de consumo das populações dos municípios. As demais variáveis discutidas neste estudo apresentaram 
algumas associações significativas por meio da análise de correlações no conjunto de dados sobre os municípios dedicados à cotonicultura convencional ou orgânica. O Quadro 7 mostra os coeficientes de correlação para os dados sobre os municípios dedicados à cotonicultura convencional, destacando as associações mais fortes e significantes.

Quadro 7-Correlações para os municípios dedicados à cotonicultura convencional

\begin{tabular}{|l|c|c|c|c|c|c|c|c|c|c|c|}
\hline & PIB & $\begin{array}{c}\text { PIB } \\
\text { agro. }\end{array}$ & $\begin{array}{c}\text { PIB } \\
\text { Ind. }\end{array}$ & $\begin{array}{c}\text { Pop. } \\
\text { total }\end{array}$ & $\begin{array}{c}\text { PIB per } \\
\text { cap. } \\
\text { rural }\end{array}$ & $\begin{array}{c}\text { PIB per } \\
\text { cap. }\end{array}$ & IDH & IDH-E & Gelad. & TV & EvDS \\
\hline PIB & 1 & & & & & & & & & & \\
\hline PIB agro. &, $596^{*}$ & 1 & & & & & & & & & \\
\hline PIB Ind. &, $882^{* *}$ &, 491 & 1 & & & & & & & & \\
\hline Pop. total &,- 388 &,$- 626^{*}$ &,- 177 & 1 & & & & & & & \\
\hline PIB per cap. rural &, 502 &, $907^{* *}$ &, 334 &,$- 829^{* *}$ & 1 & & & & & & \\
\hline PIB per cap. &, $913^{* *}$ &, $762^{* *}$ &, $742^{* *}$ &,$- 709^{* *}$ &, $779^{* *}$ & 1 & & & & & \\
\hline IDH &, 350 &, 537 &, 287 &,- 445 &, $627^{*}$ &, 518 & 1 & & & & \\
\hline IDH-E &, 408 &, $588^{*}$ &, 293 &,- 377 &, $602^{*}$ &, 532 &, $948^{* *}$ & 1 & & & \\
\hline Geladeira &, 162 &, $692^{*}$ &, 168 &,- 371 &, $620^{*}$ &, 338 &, $713^{* *}$ &, $657^{*}$ & 1 & & \\
\hline TV &, 180 &, $670^{*}$ &, 306 &,- 288 &, 545 &, 315 &, $640^{*}$ &, $589^{*}$ &, $952^{* *}$ & 1 & \\
\hline EvDS &, $904^{* *}$ &, $682^{*}$ &, $700^{*}$ &,$- 693^{*}$ &, $721^{* *}$ &, $979^{* *}$ &, 446 &, 465 &, 193 &, 150 & 1 \\
\hline
\end{tabular}

* A correlação é significativa no nível 0,05 (bilateral).

** A correlação é significativa no nível 0,01 (bilateral).

Fonte: Elaborado pelos autores.

O crescimento econômico demonstrado no PIB dos municípios no período dos anos 2000 a 2010 está fortemente associado aos resultados do setor industrial e do PIB per capita. Também há uma forte associação positiva entre os resultados do setor agropecuário e o PIB per capita da população rural. Há, entretanto, uma forte associação entre o aumento da população total dos municípios e a diminuição do PIB per capita da população rural. Outra associação forte é entre a evolução no nível de educação da população e a evolução do IDH do município. Embora o IDH também seja composto pelos níveis de renda e longevidade da população, além da educação, essas associações não foram mostradas na análise de correlações. Esses resultados contrariam a crítica apontada por Souza (1999), de que os índices utilizados para a avaliação do desenvolvimento humano são analisados em razão da renda dos indivíduos, atribuindo maior importância ao crescimento econômico. Quando se trata do padrão de consumo da população, outra forte associação encontrada diz respeito ao aumento na quantidade de domićlios com geladeiras e televisões. Nos municípios dedicados à cotonicultura convencional, o aumento da evolução orientada para o desenvolvimento sustentável é fortemente associado aos resultados de evolução do PIB e do PIB per capita da população total.

A análise de correlações sobre os dados dos municípios dedicados à cotonicultura convencional aponta para a ausência de associações entre os resultados de dimensões distintas do desenvolvimento. Todas as associações fortes e significativas encontradas foram entre variáveis que compõem uma mesma dimensão, seja entre os componentes do PIB na dimensão econômica, seja entre os componentes do IDH na dimensão social, seja entre os componentes de consumo de bens duráveis na dimensão ambiental. 
A falta de associações fortes entre variáveis das dimensões distintas coloca em dúvida a presença da propriedade de inter-relação entre as dimensões econômica, social e ambiental, que caracteriza o modelo de desenvolvimento sustentável. Por sua vez, os coeficientes de correlação para os dados sobre os municípios dedicados à cotonicultura orgânica são mostrados no Quadro 8, quando as associações mais fortes e significantes estão destacadas.

Quadro 8 - Correlações para os municípios dedicados à cotonicultura orgânica

\begin{tabular}{|c|c|c|c|c|c|c|c|c|c|c|c|}
\hline & PIB & $\begin{array}{c}\text { PIB } \\
\text { agro. }\end{array}$ & $\begin{array}{l}\text { Pop. } \\
\text { Urb. }\end{array}$ & $\begin{array}{c}\text { PIB per } \\
\text { cap. } \\
\text { rural }\end{array}$ & $\begin{array}{l}\text { PIB } \\
\text { per } \\
\text { cap. }\end{array}$ & IDH & IDH-E & Gelad. & TV & Bens & EvDS \\
\hline PIB & 1 & & & & & & & & & & \\
\hline PIB agro. &,- 404 & 1 & & & & & & & & & \\
\hline Pop. Urbana & ,480 &,- 016 & 1 & & & & & & & & \\
\hline PIB per cap. rural &,- 513 & , $970^{* *}$ &,- 103 & 1 & & & & & & & \\
\hline PIB per cap. & $845^{* *}$ &,$- 627^{*}$ & , 180 &,$- 645^{*}$ & 1 & & & & & & \\
\hline IDH &,- 027 &,- 064 & ,610* &,- 120 &,- 027 & 1 & & & & & \\
\hline IDH-E & ,051 &,- 006 &, $622^{*}$ &,- 069 & ,041 & $975^{* *}$ & 1 & & & & \\
\hline Geladeira & ,036 & 108 & ,769** & ,022 &,- 125 & ,894** & $876^{* *}$ & 1 & & & \\
\hline TV & ,248 & 290 & ,831** & 161 &,- 040 & ,736** &, $795^{* *}$ &, $878^{* *}$ & 1 & & \\
\hline Bens & ,347 & ,283 &, $883^{* *}$ & 146 & ,009 & ,620* &, $657^{*}$ &, $847^{* *}$ & ,958** & 1 & \\
\hline EvDS & 130, &,$- 639^{*}$ &,$- 607^{*}$ &,- 530 & ,543 &,- 376 &,- 379 &,$- 675^{*}$ &,$- 773^{* *}$ &,$- 814^{* *}$ & 1 \\
\hline
\end{tabular}

** A correlação é significativa no nível 0,01 (bilateral).

* A correlação é significativa no nível 0,05 (bilateral).

Fonte: Elaborado pelos autores.

Na dimensão econômica desses municípios, a evolução do PIB está fortemente associada ao crescimento dos resultados do PIB per capita. Também se observa que os resultados de crescimento econômico do setor agropecuário e do PIB per capita da população rural estão fortemente associados. Na dimensão social, a análise de correlações mostra que a evolução do IDH está fortemente associada ao crescimento no nível de educação da população, mas não mostra associações fortes com os níveis de renda e longevidade. Esses resultados contrariam novamente a crítica apontada por Souza (1999), de que os índices utilizados para a avaliação do desenvolvimento humano atribuem maior importância à renda dos indivíduos. Na dimensão ambiental, considerando os padrões do consumo da população, existem fortes associações entre a quantidade de domicílios com bens duráveis gerais e de domicílios com geladeiras e, mais fortemente, com televisões, além de forte associação com o crescimento populacional na zona urbana. As quantidades de domicílios com geladeiras e televisões também estão fortemente associadas entre si. A análise de correlações ainda aponta uma forte associação entre o crescimento populacional urbano e a quantidade de domicílios com televisões.

Quando se trata das inter-relações entre as distintas dimensões do desenvolvimento nos dados sobre os municípios dedicados à cotonicultura orgânica, não há associações fortes entre os componentes do PIB na dimensão econômica com qualquer resultado das dimensões social e ambiental. Existem, contudo, correlações entre as dimensões social e ambiental que sugerem a presença de inter-relações entre elas. A análise de correlações aponta para fortes associações entre a evolução do nível de edu- 
cação da população bem como do IDH como um todo, com o aumento de domicílios com geladeiras. Adicionalmente, para esses municípios, a evolução orientada para o desenvolvimento sustentável aparece associada fortemente à diminuição do consumo de bens duráveis em geral. Essa possível inter-relação entre as dimensões social e ambiental revela um dilema no conceito de desenvolvimento sustentável. Comumente, as melhorias nas condições sociais da população requerem uma elevação no consumo de bens duráveis importantes na promoção de qualidade de vida, que, por sua vez, gera impactos negativos no meio ambiente. Assim, para satisfazer o conceito de desenvolvimento sustentável, as melhorias nas condições sociais não podem estar associadas ao aumento dos padrões de consumo de bens duráveis, como é mostrado nos dados sobre os municípios dedicados à cotonicultura orgânica.

\section{CONCLUSÕES}

O presente estudo teve o objetivo de comparar os municípios nordestinos dedicados à cotonicultura convencional e à orgânica a partir das mudanças nos seus indicadores de desenvolvimento no período dos anos 2000 a 2010. Foi identificado que o desenvolvimento dos municípios tem obtido resultados diferentes, vinculados aos distintos paradigmas agrícolas instituídos em áreas do cerrado e da caatinga.

A comparação entre os indicadores de crescimento econômico, de desenvolvimento humano e do padrão de consumo nos munícipios estudados sinaliza uma distinção nas suas trajetórias de desenvolvimento. No período dos anos 2000 a 2010, os municípios dedicados à cotonicultura convencional, em conjunto, tiveram uma evolução no crescimento econômico e no desenvolvimento humano mais intensa do que os municípios dedicados à cotonicultura orgânica. A população desses últimos municípios, porém, teve uma evolução menor no padrão de consumo de bens duráveis do que a população nos municípios dedicados à cotonicultura convencional. O resultado negativo da evolução dos impactos ambientais causados pelo aumento mais intenso no padrão de consumo de bens duráveis nos municípios dedicados à cotonicultura convencional, entretanto, é compensado pelos resultados positivos da evolução nos indicadores de crescimento econômico e de desenvolvimento humano. Assim, o desenvolvimento dos municípios dedicados à cotonicultura convencional tem demostrado uma orientação mais forte para o modelo de desenvolvimento sustentável do que os municípios dedicados à cotonicultura orgânica, falseando a proposição apresentada neste estudo. Essa comparação põe em dúvida a capacidade de a agricultura orgânica se distinguir da convencional, entre outros fatores, por promover o modelo de desenvolvimento sustentável. Os resultados deste estudo, contudo, não justificam que os sistemas de agricultura convencional sejam mantidos ou reforçados. Em vez disso, conclui-se que os sistemas de agricultura orgânica, no território investigado, ainda estão em fase de institucionalização, com o potencial de transformação de seus resultados em benefícios econômicos e sociais para a população geral, a ser concretizado no futuro.

Embora as vantagens da agricultura orgânica no favorecimento da dimensão ambiental sejam evidentes, estas não parecem ser suficientes para orientar os municípios investigados ao desenvolvimento sustentável. Na agricultura orgânica, o melhor uso da terra, com cultivos que respeitam uma maior biodiversidade e livres do uso de agrotóxicos, ainda não tem o aspecto de ser capaz de proporcionar melhorias econômicas e 
sociais em escala municipal, transcendendo os benefícios para além dos grupos de agricultores e consumidores locais. Tendo em vista a urgência de buscar caminhos para o desenvolvimento sustentável, novas institucionalizações são importantes, estabelecendo arcabouços legais de incentivos e capacidades de identificar e exigir os benefícios econômicos e sociais da agricultura orgânica. Uma explicação alternativa é que, enquanto as atividades das organizações da cotonicultura orgânica têm incidências minoritárias, o conjunto de incidências de outras organizações leva o desenvolvimento dos municípios dedicados a esse paradigma a ser menos coerente com o modelo de desenvolvimento sustentável do que os municípios dedicados à cotonicultura convencional. Os resultados do estudo, contudo, não suportam essa conclusão, requerendo novas investigações.

Na cotonicultura orgânica os sistemas participativos de certificação são estabelecidos por um conjunto de relações entre produtores, que envolve dinâmicas sociais próprias em seu interior, cujos limites emolduram o espaço das interações de acordo com a concepção sociológica de espaço (SIMMEL, 2013). Assim, a distinção natural entre as áreas de cerrado, onde é cultivado o algodão convencional, e as áreas da caatinga, onde é cultivado o algodão orgânico, é reforçada por distinções sociológicas na delimitação desses espaços. É provável que aconteça a intensificação do debate entre os defensores da agricultura empresarial e da agroecologia no Nordeste, incluindo os defensores das inúmeras variações desses paradigmas de desenvolvimento rural, conforme a expansão da fronteira agrícola empresarial avance nessa região do país. A partir das discussões apresentadas neste artigo, é possível ampliar a compreensão sobre os distintos paradigmas de desenvolvimento rural.

O presente artigo teve o setor da cotonicultura como objeto de estudo. Sugere-se, para futuras pesquisas, estender a compreensão sobre as distinções no desenvolvimento de municípios dedicados a outros cultivos. Estudos de casos singulares aprofundados sobre boas práticas da agricultura orgânica ainda são necessários para compreender o potencial desse paradigma quando ele proporciona resultados expressivos, indo além das médias gerais.

\section{REFERÊNCIAS}

AGUIAR, G. A. M.; LIMA-FILHO, R. R.; TORRES-JUNIOR, A. de M. Mapitoba: a última fronteira agrícola. Mercado \& Negócios. Agroanalysis, v. 33, n. 5, p. 15-16, maio 2013.

ALTIERI, M. A.; NICHOLLS, C. I. Agroecology Scaling Up for Food Sovereignty and Resiliency. Sustainable Agriculture Reviews, 11, p. 1-29, 2012.

ANDRADA, C. F.; SATO, L. Trabalho e política no cotidiano da autogestão: a rede Justa Trama. Psicologia \& Sociedade, 26 (n. spe.), p. 3-13, 2014.

ASSIS, R. L. Desenvolvimento rural sustentável no Brasil: perspectivas a partir da integração de ações públicas e privadas com base na agroecologia. Economia Aplicada, 10(1), p. 75-89, 2006.

AUGUSTIN, S.; ALMEIDA, A. Da compreensão materialista e dialética das relações ecológicas ao conceito de desenvolvimento sustentável. Desenvolvimento em Questão, v. 4, n. 7, p. 73-94, 18 out. 2011.

BELTRÃO, N. E. de M.; VALE, L. S.; MARQUES, L. F.; CARDOSO, G. D.; SILVA, F. V. de F.; ARAÚJO, W. P. O cultivo do algodão orgânico no semi-árido brasileiro. Revista Verde de Agroecologia e Desenvolvimento Sustentável, 5(5), p. 8-13, 2010.

BIJL, R. Never waste a good crisis: Towards social sustainable development. Social Indicators Research, 102(1), p. 157-168, 2011.

BOSSLE, M. B.; NASCIMENTO, L. F.; TREVISAN, M.; FIGUEIRÓ, P. S. O comércio justo como agente mitigador das mudanças climáticas: o caso do algodão ecológico. Contextus - Revista Contemporânea de Economia e Gestão, 10(1), p. 30-47, 2012. 
CONAB. Companhia Nacional de Abastecimento. 2016. Algodão em caroço. Série Histórica de Produtividade. Safras 1976/77 a 2015/16. (Planilha). Disponível em: http://www.conab.gov.br/conteudos. php?a=1252\&t=. Acesso em: 3 maio 2016.

COOPER, D. R.; SCHINDLER, P. S. Métodos de pesquisa em administração. 7. ed. Porto Alegre: Bookman, 2003.

CRUZ, M. S.; MAIA, S. F. Desempenho da cotonicultura brasileira pós-abertura econômica. Revista Econômica do Nordeste, 39(2), p. 263-284, 2008.

FARIA, M. V. C. M.; PEREIRA, J. de A. A rede de economia solidária do algodão agroecológico: desenvolvimento humano, sustentabilidade e cooperação entre os produtores rurais do Estado do Ceará. Organizações Rurais \& Agroindustriais, 14(3), p. 395-408, 2012.

FERREIRA FILHO, J. B. de S.; ALVES, L. R. A.; VILLAR, P. M. del. Estudo da competitividade da produção de algodão entre Brasil e Estados Unidos - safra 2003/04. Revista de Economia e Sociologia Rural, 47(1), p. 59-88, 2009.

HADDAD, P. R. A concepção de desenvolvimento regional. In: HADDAD, P. R. (org.). A competitividade do agronegócio e o desenvolvimento regional no Brasil: estudos de clusters. Brasília: CNPq; Embrapa, 1999. p. 9-22.

HUETING, R.; REIJNDERS, L. Broad sustainability contra sustainability: the proper construction of sustainability indicators. Ecological Economics, 50(3), p. 249-260, 2004.

IBGE. Instituto Brasileiro de Geografia e Estatística. Cidades. 2017. Disponível em: http://www.cidades. ibge.gov.br. Acesso em: nov. 2018.

JALFIM, F.; SIDERSKY, P.; RUFINO, E.; SANTIAGO, F.; BLACKBURN, R. Geração do conhecimento agroecológico a partir da interação entre atores: a experiência do Projeto Dom Helder Camara. Agriculturas, 10(3), p. 26-34, 2013.

KENNEDY, P. M. Preparando para o século XXI. Rio de Janeiro: Campus, 1993.

LEUKHARDT, F.; ALLEN, S. How environmentally focused is the German sustainability strategy? A critical discussion of the indicators used to measure sustainable development in Germany. Environment, Development and Sustainability, 15(1), p. 149-166, 2013.

LIPOVETSKY, G.; SERROY, J. A estetização do mundo. Viver na era do capitalismo artista. São Paulo: Companhia das Letras, 2015.

MAPA. Ministério da Agricultura, Pecuária e Abastecimento. Orgânicos. 2016. Disponível em: http:// www.agricultura.gov.br/assuntos/sustentabilidade/organicos/. Acesso em: 22 nov. 2016.

MDIC. Ministério do Desenvolvimento, Indústria e Comércio Exterior. Aliceweb2. Disponível em: http:// aliceweb2.mdic.gov.br/. Acesso em: 22 nov. 2016.

OECD. Organisation for Economic Co-operation and Development. Measuring and fostering well-being and progress: The OECD Roadmap. Busan: OECD, 2009.

PEARCE, D. W.; ATKINSON, G. D. Capital theory and the measurement of sustainable development: an indicator of "weak" sustainability. Ecological Economics, 8(2), p. 103-108, 1993.

PIGNATI, W.; OLIVEIRA, N. P.; SILVA, A. M. C. da. Vigilância aos agrotóxicos: quantificação do uso e previsão de impactos na saúde-trabalho-ambiente para os municípios brasileiros. Ciênc. Saúde Coletiva, Rio de Janeiro, v. 19, n. 12, p. 4.669-4.678, dec. 2014.

PNUD. Programa das Nações Unidas para o Desenvolvimento. Atlas do Desenvolvimento Humano no Brasil. 2016. Disponível em: http://www.atlasbrasil.org.br/. Acesso em: 22 nov. 2016.

PORTO, M. F.; SOARES, W. L. Modelo de desenvolvimento, agrotóxicos e saúde: um panorama da realidade agrícola brasileira e propostas para uma agenda de pesquisa inovadora. Revista Brasileira de Saúde Ocupacional, 37(125), p. 17-50, 2012.

REES, W. E. Ecological footprints and appropriated carrying capacity: what urban economics leaves out. Environment and Urbanization, 4(2), p. 121-130, 1992.

RENNINGS, K.; WIGGERING, H. Steps towards indicators of sustainable development: Linking economic and ecological concepts. Ecological Economics, 20(1), p. 25-36, 1997.

SACHS, I. A revolução energética do século XXI. Estudos Avançados, 21(59), p. 21-38, 2007.

SACHS, I. Brasil rural: da redescoberta à invenção. Estudos Avançados, 15(43), p. 75-82, 2001.

SACHS, I. Estratégias de transição para o século XXI. In: BURSZTYN, M. (org.). Para pensar o desenvolvimento sustentável. São Paulo: Brasiliense, 1993.

SEN, A. Desenvolvimento como liberdade. São Paulo: Companhia das Letras, 2000.

SIEDENBERG, D. R. Indicadores de desenvolvimento socioeconômico: uma síntese. Desenvolvimento em Questão, 1(1), p. 45-71, 2003. 
SIMMEL, G. Sociologia do espaço. Estudos Avançados, 27(79), p. 75-112, 2013.

SOUZA, N. J. Desenvolvimento econômico. 4. ed. São Paulo: Atlas, 1999.

STIGLITZ, J.; SEN, A.; FITOUSSI, J. P. Report by the commission on the measurement of economic performance and social progress. Paris, 2009.

VAN BELLEN, H. M. As dimensões do desenvolvimento: um estudo exploratório sob as perspectivas das ferramentas de avaliação. Revista de Ciências da Administração, 12(27), p. 143-168, 2010.

VAN BELLEN, H. M. Indicadores de sustentabilidade: uma análise comparativa. 2. ed. Rio de Janeiro: FGV, 2006.

VEIGA, J. E. A emergência socioambiental. São Paulo: Senac, 2007. 